\title{
Gene Screening of 23 Japanese Families with Complete Thyroxine-Binding Globulin Deficiency: Identification of a Nucleotide Deletion at Codon 352 as a Common Cause
}

\author{
IKUO YAMAMORI, YUICHI MORI, Yoshitaka MIURA, \\ Yoshiyuki TANi, Shuji IMAMURA, Yutaka OISO and Hisao SEO* \\ The First Department of Internal Medicine, Nagoya University \\ School of Medicine, Nagoya 466, and *Department of Endocrinology \\ and Metabolism, Research Institute of Environmental \\ Medicine, Nagoya University, Nagoya 464-01, Japan
}

\begin{abstract}
Thyroxine-binding globulin (TBG) is a major thyroid hormone transport protein in human serum. Its complete deficiency (TBG-CD) is one of inherited TBG abnormalities that transmit on $\mathrm{X}$-chromosome. We previously reported a nucleotide deletion at codon 352 of the TBG gene (TBG-CDJ) in Japanese families with TBG-CD. To determine the prevalence of this mutation in Japanese with TBG-CD, 23 affected subjects (19 males and 4 females) belonging to unrelated families living in 4 major islands of Japan were analyzed with regard to the mutation at codon 352 . Their genomic DNAs were amplified by the polymerase chain reaction with allele specific primers. Nineteen male and four female subjects were shown to have the mutation as hemizygotes and heterozygotes, respectively. It is concluded that TBG-CDJ may be a common cause of TBG-CD in Japanese and might have appeared in the ancestors of the Japanese after the human race divergence.
\end{abstract}

Key words: Thyroxine-binding globulin, TBG-CDJ, Gene screening, Allele specific amplification.

(Endocrine Journal 40: 563-569, 1993)

THYROXINE-binding globulin (TBG) is a $54 \mathrm{kD}$ glycoprotein which consists of a 395 amino acid core polypeptide with 4 oligosaccharide chains [1, 2]. It is synthesized in the liver and serves as a major transport protein for thyroid hormones in human serum. It binds $70 \%$ of thyroxine $\left(\mathrm{T}_{4}\right)$ and triiodothyronine $\left(\mathrm{T}_{3}\right)$ in human serum $[2-5]$. A decrease in, or absence of, serum TBG is usually accompanied by abnormally low serum total $\mathrm{T}_{4}$ and $T_{3}$ concentrations while free $T_{4}$ and free $T_{3}$ values are unaltered, if the thyroid status remains euthyroid. Partial TBG deficiency is defined as a low TBG level in serum, while complete TBG deficiency (TBG-CD) is characterized by TBG in serum which is undetectable even with a sensitive

Received: April 16, 1993

Accepted: August 10, 1993

Correspondence to: Dr. Yuichi MORI, The First Department of Internal Medicine, Nagoya University School of Medicine, 65 Tsurumai-cho, Showa-ku, Nagoya 466, Japan assay. Several kinds of hereditary defects in the TBG molecule have been characterized [6-13]. They are inherited in X-linked fashion [5, 14, 15]. Therefore, defective TBG phenotypes are fully expressed in males. Meanwhile, females carrying both normal and TBG-CD alleles are usually phenotyped as partial TBG deficiency, and may not be recognized as TBG deficient because the extent of the decrease in TBG tends to be mild.

The TBG gene is located on the long arm of the $\mathrm{X}$-chromosome [16] and has been shown to be a member of the serpin (serine protease inhibitor) superfamily [1, 17]. Mutations in the coding regions of the TBG gene have been reported in some of the TBG variants [18-29]. As for TBGCD, replacement of Leu227 by Pro was detected in three of six French Canadian pedigrees [19]. Single nucleotide deletion at codon 165 was also reported to lead to TBG-CD in a family with an English background [21]. We have described a nucleotide deletion at codon 352 of the genomic 
TBG gene (TBG-CDJ) in Japanese subjects. A nucleotide deletion at codon 352 resulted in 22 amino acid truncation and further 22 amino acid divergence at its carboxy-terminus [22].

We have shown the existence of nucleotide deletion in six families by utilizing primer directed mutagenesis in the polymerase chain reaction (PCR)[22]. Primer directed mutagenesis with selective enzyme digestion is a useful method to use in detecting a known mutation. However, it is time consuming to digest PCR products. Recently, an easier and more direct approach, namely allele specific amplification, was established [30]. In this report, we carried out a screening program with this method to examine the prevalence of this particular mutation in 23 Japanese pedigrees with TBG-CD. A strong linkage between single nucleotide deletion at codon 352 and TBG-CD in Japanese was demonstrated.

\section{Materials and Methods}

Twenty-three families suspected of including TBG-CD subjects were analyzed in this study. In 19 of 23 families, there was an affected male subject available for study. Female subjects were chosen from the remaining 4 families.

Serum total $\mathrm{T}_{4}$, total $\mathrm{T}_{3}$ and $\mathrm{TSH}$ concentrations were determined with commercial RIA kits. Serum TBG concentrations in candidates were determined with a highly sensitive TBG enzyme immunoassay (EIA) kindly provided by Amano Pharmaceuticals Co., Nagoya, Japan. The detection limit of this kit was $0.1 \mathrm{mg} / \mathrm{L}$. The diagnosis of TBG-CD was defined as undetectable TBG in serum with this assay.

Genomic DNA was extracted from peripheral white blood cells as described previously [18]. Oligonucleotide primers specific for normal (primer $\mathrm{N}$ ) and mutant (primer M) TBG genes were chemically synthesized with a DNA synthesizer (Model 381 A, Applied Biosystems, Foster city, CA). Both primers were complementary to the sense strand of the TBG gene and were identical with each other except for the nucleotide at the 3 , end $(\mathrm{G}$ for primer $\mathrm{N}$ and $\mathrm{T}$ for primer $\mathrm{M}$, respectively). Common primer $(\mathrm{C})$ was also synthesized as complementary to the antisense strand. The sequence and location of each primer are as follows: N: (3446) 5'-TTTTCAGGCTGATCCGAAAG-3' (3427), M: (3446) 5'-TTTTCAGGCTGATCCGAAAT-3' (3426), and C: (3015) 5'-ATCCT-
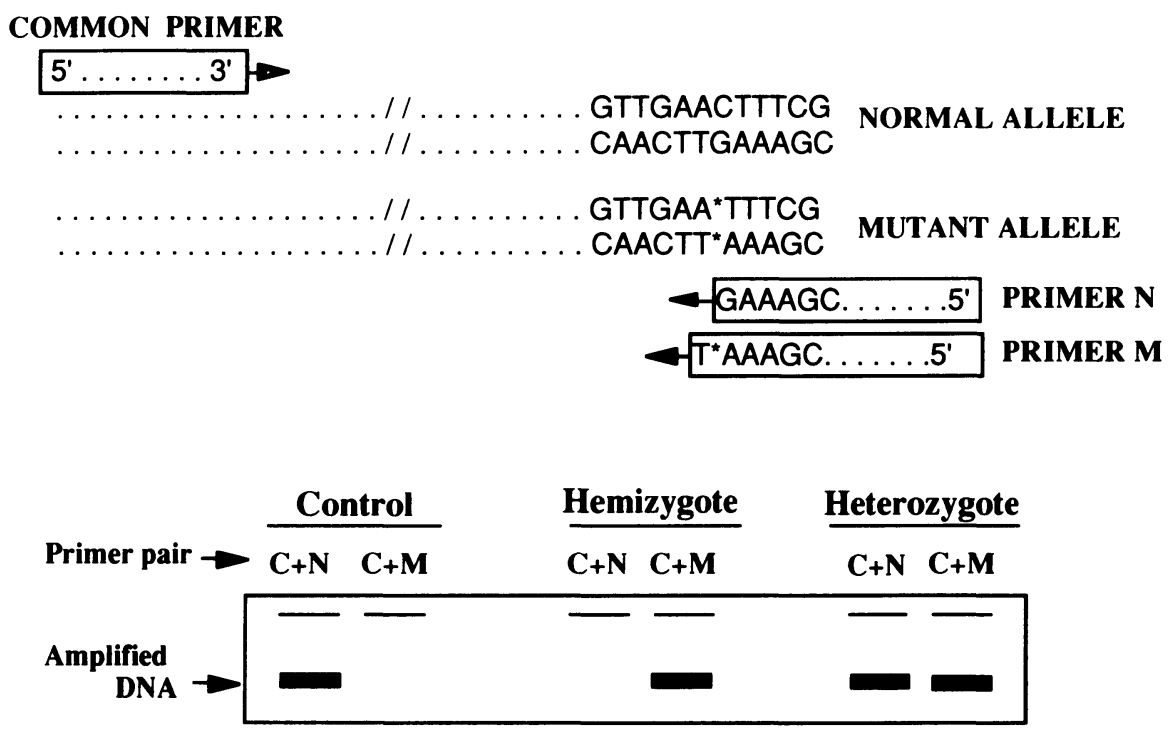

Fig. 1. The strategy of screening for the mutation with allele specific amplification. In the upper part of the figure, the relationships between primer pairs and TBG genes are shown. Asterisks in the mutant allele show a nucleotide deletion recognized in TBG-CDJ. Primer N and primer $\mathrm{M}$ were complementary to the sense strands of the normal and mutant TBG alleles, respectively. The primer pair of $\mathrm{C}$ and $\mathrm{N}$ amplifies the normal TBG allele, and the primer pair of $\mathrm{C}$ and $\mathrm{M}$ amplifies the mutant one. The relationships between amplified bands and genotypes are shown in the lower part of the figure. 
TGACCTTTATGTCCC-3' (3034), where numbers in parentheses represent the positions of the first and last nucleotides from the translation initiation codon (ATG) in the genomic TBG gene sequence (Fig. 1).

PCR was carried out as described elsewhere [25] with some modifications. Briefly, the reaction was carried out in a final volume of $100 \mu l$ with 50 pmol of each primer. One $\mu \mathrm{g}$ of genomic DNA from white blood cells was used as a template. Initial denaturation for $240 \mathrm{sec}$ at $94^{\circ} \mathrm{C}$ was followed by 30 cycles of denaturing for $90 \mathrm{sec}$ at $94^{\circ} \mathrm{C}$, annealing for $150 \mathrm{sec}$ at $56^{\circ} \mathrm{C}$, and primer extension for $210 \mathrm{sec}$ at $72^{\circ} \mathrm{C}$, with final extension for $15 \mathrm{~min}$ at $72^{\circ} \mathrm{C}$. The $\mathrm{PCR}$ products were electrophoresed on a $1.5 \%$ agarose gel, stained with ethidium bromide, and visualized by UV light. PhiX-174 phage DNA digested with Hae III (Toyobo, Tokyo, Japan) was used as a molecular weight marker. The relationships between the amplified DNA fragments and various genotypes are shown on Fig. 1. The specificity of the primers has been confirmed and reported elsewhere [31].

\section{Results}

In response to our requests of many institutions in Japan to send blood samples from TBG deficient subjects, a total of 23 (19 male and 4 female) samples from unrelated families were obtained. Their residences were widely distributed all over the main Japanese islands (Table 1). There was no consanguinity among them. Their laboratory data are summarized on Table 1. Three males (Nos. 2, 7 and 9) and one female (No. 21) treated with $l$-thyroxine had undetectable serum TSH and low

Table 1. Serum $\mathrm{TT}_{4}, \mathrm{TT}_{3}, \mathrm{TSH}$ and $\mathrm{TBG}$ concentrations and native places

\begin{tabular}{|c|c|c|c|c|c|}
\hline & $\begin{array}{c}\mathrm{TT}_{4} \\
(\mathrm{nmol} / \mathrm{L})\end{array}$ & $\begin{array}{c}\mathrm{TT}_{3} \\
(\mathrm{nmol} / \mathrm{L})\end{array}$ & $\begin{array}{c}\mathrm{TSH} \\
(\mathrm{mU} / \mathrm{L})\end{array}$ & $\begin{array}{c}\mathrm{TBG} \\
(\mathrm{mg} / \mathrm{L})\end{array}$ & RESIDENCE \\
\hline \multicolumn{6}{|l|}{ Males } \\
\hline $1^{\text {c) }}$ & 43.8 & 0.92 & 2.7 & $<0.1$ & Honshu \\
\hline $2^{\mathrm{c})}$ & 61.8 & 0.92 & $<0.1^{\mathrm{a})}$ & $<0.1$ & Honshu \\
\hline $3^{\text {c) }}$ & 46.3 & 0.92 & 1.8 & $<0.1$ & Kyushu \\
\hline $4^{\mathrm{c})}$ & 41.2 & 0.92 & 0.5 & $<0.1$ & Honshu \\
\hline 5 & 16.7 & 0.76 & 6.0 & $<0.1$ & Kyushu \\
\hline 6 & 32.2 & 0.92 & 1.0 & $<0.1$ & Honshu \\
\hline 7 & 27.0 & 0.61 & $<0.1^{\text {a) }}$ & $<0.1$ & Honshu \\
\hline 8 & 46.3 & 0.92 & 0.1 & $<0.1$ & Honshu \\
\hline 9 & 28.3 & 0.31 & $<0.1^{a)}$ & $<0.1$ & Honshu \\
\hline 10 & 29.6 & 1.04 & 0.5 & $<0.1$ & Honshu \\
\hline 11 & 43.8 & 0.90 & 0.6 & $<0.1$ & Kyushu \\
\hline 12 & 42.5 & 0.22 & 1.7 & $<0.1$ & Kyushu \\
\hline 13 & $<16.7$ & $<0.31$ & 1.8 & $<0.1$ & Honshu \\
\hline 14 & 9.3 & 1.06 & 1.8 & $<0.1$ & Shikoku \\
\hline 15 & 21.9 & 0.76 & 1.3 & $<0.1$ & Shikoku \\
\hline 16 & 64.4 & 0.92 & 2.7 & $<0.1$ & Honshu \\
\hline 17 & 46.3 & 1.21 & 2.8 & $<0.1$ & Hokkaido \\
\hline 18 & 39.9 & 1.10 & 1.8 & $<0.1$ & Honshu \\
\hline 19 & 30.9 & 1.09 & 2.8 & $<0.1$ & Kyushu \\
\hline \multicolumn{6}{|l|}{ Females } \\
\hline $20^{\mathrm{c})}$ & 60.5 & 1.38 & 3.0 & 7.8 & Honshu \\
\hline $21^{\text {c) }}$ & 55.3 & 1.22 & $<0.1^{\text {a) }}$ & 11.0 & Honshu \\
\hline 22 & 32.2 & 0.92 & 1.8 & 4.4 & Honshu \\
\hline 23 & 97.8 & 3.48 & $<0.1^{\mathrm{b})}$ & 5.0 & Honshu \\
\hline Normal ranges & $64.4-167.3$ & $1.07-2.91$ & $0.5-3.5$ & $15.6-29.1$ & \\
\hline
\end{tabular}

Total $\mathrm{T}_{4}\left(\mathrm{TT}_{4}\right)$, Total $\mathrm{T}_{3}\left(\mathrm{TT}_{3}\right)$ and $\mathrm{TSH}$ were measured with commercial RIA kits. TBG was determined by means of a highly sensitive EIA as described in Materials and Methods. As the native place of the subjects, the names of the 4 major islands of Japan are indicated under "residence". a) under $l$-thyroxine supplementation therapy for primary hypothyroidism. b) untreated hyperthyroidism. c) previously reported in Ref [22]. 


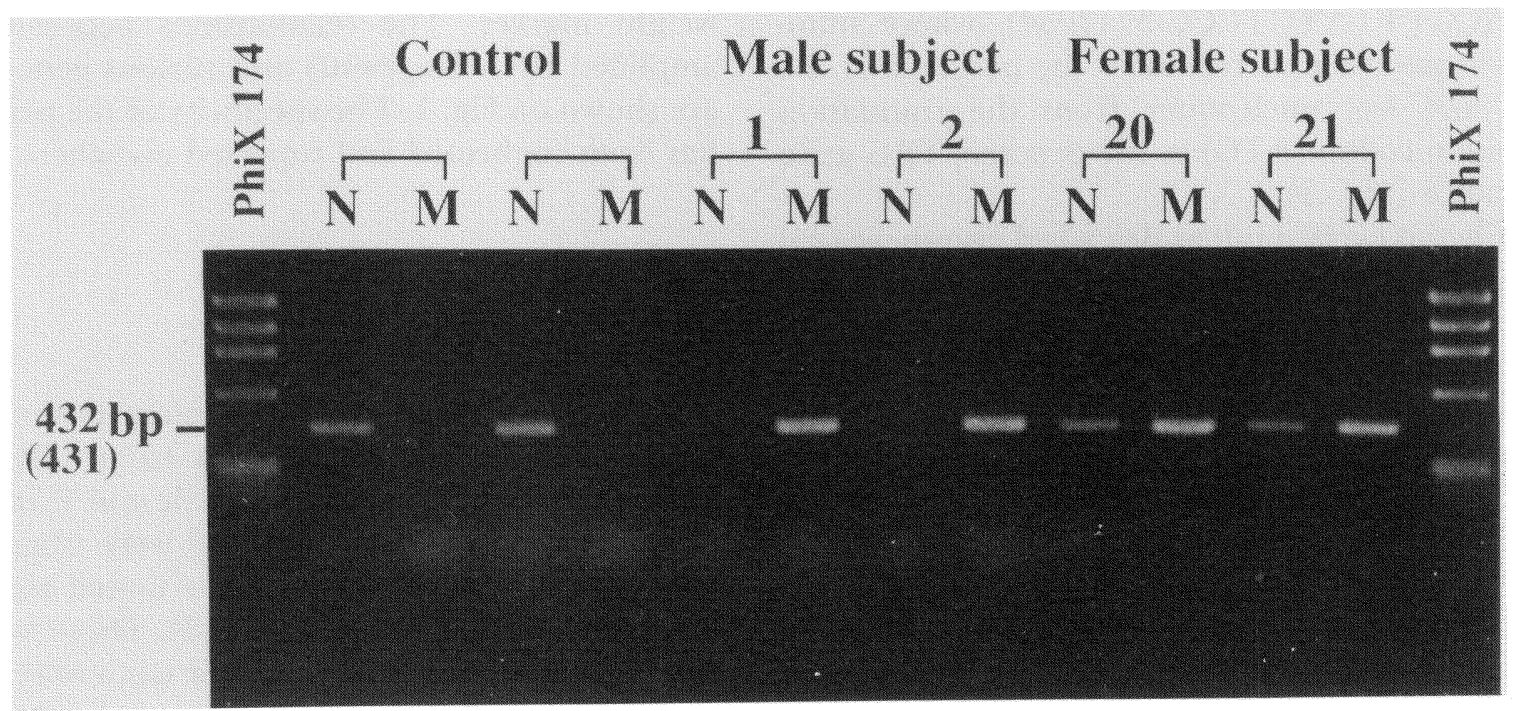

Fig. 2. Detection of normal and TBG-CDJ mutant allele by means of allele specific amplification. DNA samples from 2 control subjects were amplified only with a primer pair of $\mathrm{C}$ and $\mathrm{N}$ (lane $\mathrm{N}$ ). DNAs from affected males (Nos. 1 and 2), hemizygous for TBG-CDJ, were amplified only with a primer pair of $\mathrm{C}$ and $\mathrm{M}$ (lane M). Affected females (No. 20, 21), heterozygous of normal and mutant alleles, were amplified with both primer pairs (lanes $\mathrm{N}$ and M). PhiX 174 digested with Hae III served as a molecular weight marker.

total $\mathrm{T}_{4}$ and/or total $\mathrm{T}_{3}$ levels. Also a severe hyperthyroid subject (No. 23) with a suppressed serum TSH level had normal total $\mathrm{T}_{4}$ and slightly increased total $T_{3}$. Serum TBG levels of all males were below the detection limit $(0.1 \mathrm{mg} / \mathrm{L})$ of the EIA, indicating that they were hemizygotes of TBG-CD. Four females were shown to have decreased serum TBG $(7.8,11.0,4.4$ and 5.0 $\mathrm{mg} / \mathrm{L})$.

Their genomic DNAs were extracted from the peripheral white blood cells and subjected to polymerase chain reaction with allele specific primers. As shown in Fig. 2, a 431 base pair fragment amplified with the primer pair of $\mathrm{C}$ and $M$ was clearly demonstrated at lane $M$ of male subjects. A pair of primers, $\mathrm{C}$ and $\mathrm{N}$, gave no bands at 432 base pairs in any of them (lane $\mathrm{N}$ in Fig. 2). These results indicate that two male subjects $($ No. 1, 2) have the nucleotide deletion on their genomic DNAs as hemizygotes. In the other 17 male subjects also, this mutation was detected (data not shown).

In all 4 female subjects, PCR utilizing both primers pairs ( $\mathrm{C}$ and $\mathrm{N}, \mathrm{C}$ and $\mathrm{M}$ ) produced normal and mutant bands (432 and 431 base pairs, respectively). In Fig. 2, the results for two female subjects (No. 20, 21) are shown. Thus, it was indicated that they were heterozygotes for normal and TBG-CD alleles regarding this mutation.
Their decreased TBG was due to this heterozygosity.

Thus the same mutation at codon 352 in the TBG gene was demonstrated in all the 23 TBGdeficient subjects analyzed in this study. In contrast, genomic DNA from an unaffected subject with a normal serum TBG concentration led to the amplification of the DNA fragment only with a $\mathrm{C}$ and $\mathrm{N}$ primer pair, not with a $\mathrm{C}$ and $\mathrm{M}$ pair (Fig. 2, control).

\section{Discussion}

Three kinds of mutations have been reported to manifest inherited TBG-CD. Firstly, replacement of Leu227 by Pro was detected in three of six French Canadian pedigrees [19]. Then, single nucleotide deletions at codon 165 in a family with an English background [21] and at codon 352 in Japanese [22] were also shown to lead to this hereditary condition.

As the mutation at codon 352 does not create or eliminate a recognition site for restriction enzymes in the TBG gene, we cannot utilize the standard analysis of restriction fragment length polymorphism. In a previous study we detected the mutation by generating a novel recognition sequence in the 
mutant gene by the method of primer directed mutagenesis [22]. In this study, we employed allele specific amplification because of its simplicity. The screening of 23 subjects belonging to unrelated Japanese families with inherited TBG-CD has revealed that all families harbored the single nucleotide deletion at codon 352 without exception. It is concluded that TBG-CDJ may be a common cause of TBG-CD in Japanese. Furthermore it has been detected only in Japanese. Therefore it is postulated that TBG-CDJ might have appeared in the ancestors of the Japanese at an early stage after the divergence of the human races. Because defects in the TBG molecule cause no disabilities or disadvantages in the affected subjects, the mutation should have been well preserved. This could explain the higher frequency of the TBG-CD in Japanese than in Caucasians [32-35].

The mechanism by which this mutation causes the loss of immunoreactivity and biological activity had been evaluated in an expression experiment with mammalian cells [36]. TBG-CDJ was synthesized as a truncated molecule and retained within the rough endoplasmic reticulum, resulting in a complete absence of secretion.

Further study on the prevalence of this muta- tion in Orientals, especially in Mongoloids, may provide information on the origin of this mutation as well as of the Japanese race itself.

\section{Acknowledgements}

We are indebted to Drs. Tsuneyoshi Baba of Nagasaki University, Kiyoshi Hashizume of Shinshu University, Yoshihumi Hirooka of Aichi Medical College, Nobuko Kaise of Tohoku University, Mitsuro Niinomi of National Nagoya Hospital, Tsuneo Nishizaki of Kyoritsu General Hospital, Osamu Noguchi of Sakuragaoka Hospital, Ken Okamura of Kyushu University, Yoshihisa Shirakawa of Tokushima University, Junta Takamatsu of Osaka Medical College, Kyoko Takeda of Kochi Medical School and Mitsuaki Yoshioka of Niigata Prefectural Central Hospital for providing blood from their patients. We are grateful to Dr. Samuel Refetoff of Chicago University for technical advice. We also thank Mr. Shigeki Kimura of Amano Pharmaceutical Co., Nagoya, Japan for kindly providing a highly sensitive EIA kit for TBG determination.

\section{References}

1. Flink IL, Bailey TJ, Gustafson TA, Markham BE, Morkin E (1986) Complete amino acid sequence of human thyroxine-binding globulin deduced from cloned DNA-Close homology to the serine antiproteases. Proc Natl Acad Sci USA 83: 7708-7712.

2. Bartalena L (1990) Recent achievements in studies on thyroid hormone binding proteins. Endocr Rev 11: 47-64.

3. Refetoff S, Larsen R (1989) Transport, cellular uptake, and metabolism of thyroid hormone. In: DeGroot LJ (ed) Endocrinology. 2nd ed. Saunders, Philadelphia, vol 1: 541-561.

4. Robbins J, Edelhoch H (1986) Thyroid hormone transport proteins-Their nature, biosynthesis, and metabolism. In: Ingbar $\mathrm{SH}$, Braverman LE (eds) Werner's the Thyroid. 5th ed. Lippincott, Philadelphia: 116-127.

5. Burr WA, Ramsden DB, Hoffenberg R (1980) Hereditary abnormalities of thyroxine-binding globulin concentration. $Q J$ Med 49: 295-313.

6. Refetoff S, Selenkow HA (1968) Familial thyroxine-binding globulin deficiency in a patient with Turner's syndrome (XO). Genetic study of a kindred. N Engl J Med 278: 1081-1087.

7. Daiger SP, Rummel DP, Wang L, Cavalli-Sforza LL (1981) Detection of genetic variation with radioactive ligands IV. X-linked, polymorphic variation of thyroxine-binding globulin (TBG). Am J Hum Genet 33: 640-648.

8. Refetoff S, Murata Y (1985) X-chromosome linked inheritance of the variant thyroxine-binding globulin in Australian Aborigines. J Clin Endocrinol Metab 60: 356-360.

9. Takamatsu J, Ando M, Weinberg M, Refetoff S (1986) Isoelectric variant thyroxine-binding globulin in American blacks. Increased heat lability and reduced serum concentration. J Clin Endocrinol metab 63: 80-87.

10. Takamatsu J, Refetoff S, Charbonneau M, Dussault JH (1987) Two new inherited defects of the thyroxine-binding globulin (TBG) molecule presenting as partial TBG deficiency. J Clin Invest 79: 833-840.

11. Sarne DH, Refetoff S, Nelson JC, Linarelli LG (1989) A new inherited abnormality of thyroxinebinding globulin (TBG-San Diego) with decreased 
affinity for thyroxine and triiodothyronine. J Clin Endocrinol Metab 68: 114-119.

12. Refetoff S (1989) Inherited thyroxine-binding globulin abnormalities in man. Endocr Rev 10: 275-293.

13. Janssen OE, Bertenshaw R, Takeda K, Weiss R, Refetoff $S$ (1992) Molecular basis of inherited thyroxine-binding globulin defects. Trends Endocrinol Metab 3: 49-53.

14. Nikolai TF, Seal US (1966) X-chromosome linked familial decrease in thyroxine-binding globulin activity. J Clin Endocrinol Metab 26: 835-841.

15. Refetoff S, Robin NI, Alper CA (1972) Study of four new kindreds with inherited thyroxinebinding globulin abnormalities. J Clin Invest 51: 848-867.

16. Trent JM, Flink IL, Morkin E, Van Tuinen P, Ledbetter DH (1987) Localization of the human thyroxine-binding globulin gene to the long arm of the X chromosome (Xq21-22). Am J Hum Genet 41: 428-435.

17. Weiss R, Mori Y, Takeda K, Seino S, Bell GI, Refetoff S (1989) Sequence of the human thyroxine-binding globulin (TBG) gene and its structural homology to the serpin superfamily. Clin Res 37: 536A (Abstract).

18. Mori Y, Refetoff S, Flink IL, Charbonneau M, Murata Y, Seo H, Morkin E, Dussault JH (1988) Detection of the thyroxine-binding globulin (TBG) gene in six unrelated families with complete TBG deficiency. J Clin Endocrinol Metab 67: 727-733.

19. Mori Y, Takeda K, Charbonneau M, Refetoff S (1990) Replacement of Leu227 by Pro in thyroxine-binding globulin (TBG) is associated with complete TBG deficiency in three of eight families with this inherited defect. J Clin Endocrinol Metab 70: 804-809.

20. Janssen OE, Refetoff S (1992) In vitro expression of thyroxine-binding globulin (TBG) variants-Impaired secretion of TBG PRO-227 but not TBG PRO-1 13. J Biol Chem 267: 13998-14004.

21. Li P, Janssen OE, Takeda K, Bertenshaw RH, Refetoff S (1991) Complete thyroxine-binding globulin (TBG) deficiency caused by a single nucleotide deletion in the TBG gene. Metabolism. 40: 1231-1234.

22. Yamamori I, Mori Y, Seo H, Hirooka Y, Imamura S, Miura Y, Matsui N, Oiso Y (1991) Nucleotide deletion resulting in frameshift as a possible cause of complete thyroxine-binding globulin deficiency in six Japanese families. J Clin Endocrinol Metab 73: 262-267.

23. Mori Y, Seino S, Takeda K, Flink IL, Murata Y, Bell GI, Refetoff S (1989) A mutation causing reduced biological activity and stability of thyroxine-binding globulin probably as a result of abnormal glycosylation of the molecule. Mol Endocrinol 3: 575-579.
24. Kambe F, Seo H, Mori Y, Murata Y, Janssen OE, Refetoff S, Matsui N (1992) An additional carbohydrate chain in the variant thyroxine-binding globulin-Gary (TBG- Asn ${ }^{96}$ ) impairs its secretion. Mol Endocrinol 6: 443-449.

25. Takeda K, Mori Y, Sobieszczyk S, Seo H, Dick M, Watson F, Flink IL, Seino S, Bell GI, Refetoff S (1989) Sequence of the variant thyroxine-binding globulin of Australian Aborigines-Only one of two amino acid replacements is responsible for its altered properties. J Clin Invest 83: 1344-1348.

26. Waltz MR, Pullman TN, Takeda K, Sobieszczyk P, Refetoff S (1990) Molecular basis for the properties of the thyroxine-binding globulin-slow variant in American blacks. J Endocrinol Invest 13: 343-349.

27. Janssen OE, Takeda K, Refetoff S (1991) Sequence of the variant thyroxine binding globulin (TBG) in a Montreal family with partial TBG deficiency. Hum Genet 87: 119-122.

28. Bertenshaw R, Takeda K, Refetoff S (1991) Sequencing of the variant thyroxine-binding globulin (TBG)-Quebec reveals two nucleotide substitutions. Am J Hum Genet 48: 741-744.

29. Bertenshaw R, Sarne D, Tornari J, Weinberg M, Refetoff S (1992) Sequencing of the variant thyroxine-binding globulin (TBG)-San Diego reveals two nucleotide substitutions. Biochim Biophys Acta 1139: 307-310.

30. Nichols WC, Liepnicks JJ, Mckusick VA, Benson MD (1989) Direct sequencing of the gene for Maryland/German familial amyloidotic polyneuropathy type II and genotyping by allele-specific enzymatic amplification. Genomics 5: 535-540.

31. Noguchi T, Yamamori I, Takamatsu J, Nakajima T, Mori Y, Kumahara Y (1993) Hereditary complete thyroxine-binding globulin deficiency-Identification by $\mathrm{T}_{3}$ resin uptake test and DNA analysis. Intern Med (Tokyo) In Press.

32. Ito Y, Kuroda Y, Enomoto H (1980) The method of $T_{4}$ radioimmunoassay using filter paper blood samples and its application for the early detection of neonatal hypothyroidism. Folia Endocrinol Japon 56: 786-803 (In Japanese).

33. Nohara Y, Kato K, Kashio N, Matsuura N, Takasugi N (1980) Determination of subjects with abnormal $\mathrm{T}_{4}$ values found on neonatal screening. Folia Endocrinol Japon 56: 462 (Abstract) (In Japanese).

34. Dussault JH, Morissette J, Letarte J, Guyda H, Laberge C (1978) Modification of a screening program for neonatal hypothyroidism. $J$ Pediatr 92: 274-277.

35. Fisher DA, Dussault JH, Foley Jr TP, Klein AH, LaFranchi S, Larsen PR, Mitchel ML, Murphey WH, Walfish PG (1979) Screening for congenital hypothyroidism-Result of screening one million North American infants. J Pediatr 94: 700-705.

36. Miura Y, Kambe F, Yamamari I, Tani Y, Mori Y, 
Murata Y, Seo H, Oiso Y, Matsui N (1992) Retention within the rough endoplasmic reticulum may be the cause of complete thyroxine-binding globulin deficiency in Japanese (TBG-CDJ) - As evidenced by endoglycosidase $\mathrm{H}$ sensitivity. Thyroid 2 (Suppl 1): S-37 (Abstract). 